\title{
Expression of MicroRNA 146a, 155, 181 and 223 in febrile seizure
}

\author{
Kürşat Bora Çarman ${ }^{1 \oplus}$, Yasemin Karal2 ${ }^{2 \oplus}$, Gül Gülen Mert ${ }^{3 \oplus}$, Arzu Ekici ${ }^{4 \oplus}$, \\ Peren Perk ${ }^{5}$, Didem Arslantaş ${ }^{6 \oplus}$, Coskun Yarar ${ }^{1 \oplus}$, Ener Çağrı Dinleyici ${ }^{7}$ \\ ${ }^{1}$ Division of Pediatric Neurology, Eskişehir Osmangazi University Faculty of Medicine, Eskişehir; ${ }^{2}$ Department of Pediatrics, Trakya \\ University Faculty of Medicine, Edirne; ${ }^{3}$ Department of Pediatric Neurology, Çukurova University Faculty of Medicine, Adana; \\ ${ }^{4}$ Department of Pediatric Neurology, Yüksek İhtisas Hospital, Bursa; ${ }^{5}$ Gaziantep Children's Hospital, Gaziantep; Departments of \\ ${ }^{6}$ Public Health and ${ }^{7}$ Pediatrics, Eskişehir Osmangazi University Faculty of Medicine, Eskişehir, Turkey.
}

\begin{abstract}
Background. We studied microRNAs (miRNAs) -146a, -155, -181 and -223 expressions and proinflammatory cytokine levels in children with Febrile seizure (FS) and compared to febrile controls.

Methods. This prospective multicenter study examined representative populations in eight different cities in Turkey between June 30, 2018 and July 1, 2019. Blood samples were taken from all children at presentation. The real time (RT) polymerase chain reaction (PCR) were used to measure the expressions of microRNAs and tumor necrosis factor alpha (TNF- $\alpha$ ), interleukin 1 beta (IL-1 $\beta$ ), and interleukin 6 (IL-6) levels were studied by enzyme-linked immuno-sorbent assay.

Results. The study was conducted with 60 children; 30 children with FS and 30 children in the febrile control group. The seizure was classified as simple FS in $73.3 \%$ and half of the children were experiencing their first FS episode.

Although the expression levels of miRNAs-146a, -181a and -155 were higher in febrile seizure patients, only miRNAs 146a level was significantly higher in FS patients. Serum TNF- $\alpha$, IL-1 $\beta$, IL-6 levels were higher in the FS group than the controls. The results of statistical analysis showed that there were correlations within miRNA expressions in children with FS. No differences were found considering miRNA expression between FS type, number of FS experienced.
\end{abstract}

Conclusions. miRNAs-146a, -181a, -155 and -223 may be involved in FS pathogenesis. Altered miRNA expression levels might be an adaptive response to inflammation. New therapeutic approaches might be developed based on miRNA expressions in children with FS.

Key words: febrile seizure, microRNA, proinflammatory cytokine.

The pathophysiology of febrile seizure (FS) is not fully understood, and research results have revealed a complex interaction of inflammation, genetic tendency and cytokines. Tumor necrosis factor alpha (TNF- $\alpha$ ), interleukin 1 beta (IL-1 $\beta$ ) and interleukin 6 (IL-6) are the main cytokines involved in the pathophysiology of FS.,

\footnotetext{
$凶$ Kürşat Bora Çarman

kbcarman@gmail.com
}

Received 15th October 2020, revised 3rd December 2020, accepted 24th December 2020.
MicroRNAs (miRNAs) are small non-coding RNAs, and their main target is messenger RNAs (mRNAs). More than two thousand miRNAs have been identified thus far, and more than half of these are expressed in the human brain. ${ }^{3}$ Alteration in the expression levels of specific miRNAs has been suggested as a possible cause in the pathophysiology of different diseases, such as cancer, Parkinson disease and epilepsy. 3,4

miRNAs have emerged as potent regulators of inflammation. ${ }^{4,5}$ For example, miRNA-146a is the first inflammation-associated miRNA. 
It has been shown to regulate the expression of toll-like receptors and cytokine pathways. Both miRNA-146a and IL-1 $\beta$ were upregulated in astrocytes in epilepsy models. The purpose of miRNA-146a expression in astrocytes may be to modulate the inflammatory response stimulated by pro-inflammatory cytokine IL$1 \beta .{ }^{5,6}$ miRNA-146a is significantly upregulated in tissues obtained from patients with mesial temporal lobe epilepsy (MTLE), more than half of whom had a history of FS in childhood. ${ }^{5-7}$ In addition, increased expression of miRNA-155 has been observed in the hippocampal tissue of children with MTLE, and this increase was correlated with an increase in TNF- $\alpha$ in nervous tissue. $^{8}$

Respiratory viral infections are the most common cause of fever in children with FS. ${ }^{9}$ The miRNA system modulates viral replication and pathogenesis. ${ }^{10}$ Studies have shown that many miRNAs have high expression, whereas thirtyfive miRNAs have low expression following adenovirus infection, which commonly affects children with FS. Downregulation of miRNA146a and miRNA-155 in patients with influenza A virus has also been reported. ${ }^{11}$ The role of miRNAs in the pathophysiology of FS has rarely been investigated. ${ }^{12,13}$ Thus, in the present study, we aimed to investigate miRNAs 146a, 155, 181 and 223 expressions in children with FS and compare these to levels in febrile controls.

\section{Material and Methods}

This prospective multicenter study was conducted in eight different cities between June 30, 2018 and July 1, 2019. The study was approved by the Local Ethical Committee of Eskisehir Osmangazi University (IRB Number 2020/55, Date: 02.03.2020) and supported by a university research grant. Written informed consents were obtained from the parents of all the participating children.

At each site, all children with seizures were evaluated for a one-year period, and children with FS were enrolled in the study. FS in each child was classified. ${ }^{14}$ The childrens' previous medical history and demographical features were recorded. Detailed physical examinations were performed, including neurological examinations. The control group included agematched children who were diagnosed with febrile disease but who did not have seizures and had no known history of previous FS. The febrile diseases include respiratory tract infections, gastrointestinal infections and other viral infections.

Blood samples (3 cc) were obtained within one hour after the seizure in a serum separation tube (SST). The serum samples were immediately separated by centrifugation and stored at $-80{ }^{\circ} \mathrm{C}$ in a freezer.

Cytokine analysis: All those stored were analyzed using commercially available assay kits according to the manufacturer's instructions. Serum IL-6 values were determined using ELISA technique (Bioassay Technology Laboratory, Shanghai, China). The minimum detectable IL-6 concentration was 0.092 pg/ml. Serum TNF- $\alpha$ values were also measured using an ELISA technique (Bioassay Technology Laboratory, Shanghai, China). The minimum detectable TNF- $\alpha$ concentration was $1.52 \mathrm{pg} /$ $\mathrm{ml}$. Serum IL-1 $\beta$ values were determined using ELISA technique (Bioassay Technology Laboratory, Shanghai, China). The minimum detectable IL-1 $\beta$ concentration was $0.02 \mathrm{pg} / \mathrm{mL}$. The intraassay coefficient of variations for all three cytokines were below $8 \%$, and inter-assay coefficient of variations were below $10 \%$.

Total RNA Extraction: Total RNA extraction was done by using a TRIzol ${ }^{\text {TM }}$ Reagent kit according to the manufacturer's protocol for serum/ plasma samples. In short, $200 \mu \mathrm{l}$ human serum was added into $1000 \mu \mathrm{l}$ TRIzol $^{\mathrm{TM}}$ reagent and after vortexing incubated at room temperature for $2 \mathrm{~min}$. Following the phase separation by adding chloroform with centrifugation, upper aqueous phase (containing RNA) was mixed with $500 \mu \mathrm{l}$ of 2-Propanol. The supernatant was discarded after centrifugation. The pellet was resuspended with $75 \%$ ethanol, centrifuged 
and air dry. Thirty $\mu$ l of nuclease-free elution buffer was carefully added to resuspend the pellet. Then the amount of nucleic acid in the total RNA samples by fluorescence spectrophotometry (Colibri Microvolume Spectrometer, Titertek-Berthold, Germany) was measured. RNA concentrations ranged from 100 to $400 \mathrm{ng} / \mu \mathrm{l}$, and the total RNA purity was verified using of A260/A280 ratios (range 1.811.97). The integrity of the serum RNA could not be assessed by gel electrophoresis because the levels were very low amounts in the serum and plasma. DNase I enzyme (Arcticzymes, Norway) was used to remove DNA from serum RNA by fixing $100 \mathrm{ng} / \mu \mathrm{l}$.

Poly(A) Polymerisation and Reverse Transcription: In this step, poly(A) tails were added to the $3^{\prime}$ end of miRNAs with Poly(A) Polymerase, Yeast $(\mathrm{ABM})$ kit. The reaction mixture consisted of $5 \mu \mathrm{l}$ of $5 \mathrm{X}$ buffer, $11.25 \mu \mathrm{l}$ of nuclease-free water, $1 \mu \mathrm{l}$ Poly(A) Polymerase $(1 \mathrm{U} / \mu \mathrm{l}), 1.25 \mu \mathrm{l}$ of ATP $(10 \mathrm{mM}), 2.5 \mu \mathrm{l}$ of $\mathrm{MnCl} 2(25 \mathrm{mM}), 5 \mu \mathrm{l}(500 \mathrm{ng})$ of RNA for a 25 $\mu \mathrm{l}$ reaction and incubate at $37{ }^{\circ} \mathrm{C}$ for $20 \mathrm{~min}$ and $65{ }^{\circ} \mathrm{C}$ for $20 \mathrm{~min}$ in in Veriti ${ }^{\mathrm{TM}}$ 384-Well Thermal Cycler (Life Technologies, Carlsbad, CA, USA). These modified miRNAs were then reverse transcribed using a stem-loop poly(A) tailed RT-PCR. The reaction mixture consisted of $2 \mu \mathrm{l}$ of M-MuLV reaction buffer (2x), 10.5 $\mu \mathrm{l}$ of nuclease-free water, $1 \mu \mathrm{l}$ of M-MuLV RT enzyme $(200 \mathrm{U} / \mu \mathrm{l}), 1.25 \mu \mathrm{l}$ of $\mathrm{dNTP}(10 \mathrm{mM})$, $1 \mu \mathrm{l}$ of miRNA specific RT primer $(10 \mathrm{mM})$, $0.25 \mu \mathrm{l}$ of RNase Inhibitor $(40 \mathrm{U} / \mu \mathrm{l})$ and $5 \mu \mathrm{l}$ of poly(A) tailed RNA for a $20 \mu \mathrm{l}$ reaction. Reverse transcription was performed for OneScript ${ }^{\circledR}$ Plus cDNA Synthesis (ABM) in in Veriti ${ }^{\mathrm{TM}}$ 384-Well Thermal Cycler (Life Technologies, Carlsbad, California, United States) at $42{ }^{\circ} \mathrm{C}$ for $60 \mathrm{~min}$, heat inactivate the reverse transcriptase at $85{ }^{\circ} \mathrm{C}$ for $10 \mathrm{~min}$. Then the product was immediately cooled to $4{ }^{\circ} \mathrm{C}$ and stored at $-20^{\circ} \mathrm{C}$.

Detection of miRNAs by qPCR: The RT-qPCR reactions were performed and monitored using a real-time ABI Prism 7500 FAST qPCR System from Applied BioSystems (Life Technologies, Carlsbad, California, United States). Real time
PCR was performed in duplicate for each miRNA and included non-template control. Human small non-coding RNAs miR181a, miR155, mir146a and miR223 designs (Diagen, Ankara, Turkey) were used for study and endogenous control small ncRNA SNORD47 was chosen as the internal control for normalization. The PCR reaction consisted of, $10 \mu \mathrm{l}$ of Diagen $2 \mathrm{X}$ PCR Master Mix solution (2x), $3.5 \mu$ l of nuclease-free water, $3.5 \mu \mathrm{l}$ of miRNA specific Primer Mix and $3 \mu \mathrm{l}$ of poly(A) tailed miRNA for $20 \mu \mathrm{l}$ reaction. Amplification was performed and monitored using a real-time instrument ABI Prism 7500 FAST qPCR System from Applied BioSystems (Life Technologies, Carlsbad, California, United States) at $95^{\circ} \mathrm{C}$ for $10 \mathrm{~min}$, followed by 40 cycles at $95{ }^{\circ} \mathrm{C}$ for $10 \mathrm{sec}, 55^{\circ} \mathrm{C}$ for $30 \mathrm{sec}, 72{ }^{\circ} \mathrm{C}$ for 5 sec. Real time PCR raw fluorescence data were analyzed using 7500 Fast Software v2.0.6 with automatic baseline and threshold setting for quantification cycle $(\mathrm{Ct})$ determination. PCR amplification efficiencies test were calculated to verify the primer specificity and sensitivity by use of the formula $E=(10-1 /$ slope - 1) 9100 and to control the PCR yield was demonstrated by the synthetic miRNA sequence of each miRNA. The qPCR Ct values of the samples included in the target and control groups were calculated as fold changes in the gene expression analysis. Fold Change value is $\mathrm{qPCR}$ gene expression ratio of each sample. In this study, fold change values were calculated of the miRNAs miR181a, miR155, mir146a and miR223 with the comparative $2(-\Delta \Delta \mathrm{Ct})$ relative expression method to reference gene SNORD47. The gene expression fold change values for each gene in each sample were transformed to $\log 2$.The fact that the fold change data give extremely low or high expression gene expression coefficients affects the data distribution in statistical analyses. The purpose of logarithmic transformation is to make gene expression level more specific and to show normal distributions. ${ }^{15,16}$ In this way, the expression load is equalized in cases of overexpression and low expression of genes, and the effect of extreme values is also eliminated.

Statistical analysis: The expression levels of miRNAs and serum cytokine levels were 
presented as median, minimum and maximum values. The non-parametric tests were performed because of small sample size and the data that were not normally distributed were analyzed with Shapiro-Wilk's test. The MannWhitney U test was used to compare miRNA and cytokine levels between the two groups. To further potential any interrelationship, Spearman rank correlation test was performed. A $p$ value $<0.05$ was deemed statistically significant. The analyses were performed with SPSS for Windows 15.0 (Chicago, IL, United States)

\section{Results}

The study was conducted with 60 children: 30 children with FS and 30 children in the febrile control group. Half of the children (15 out of 30; $50 \%$ ) were experiencing their first FS episode. In $73.3 \%$ of the children $(22 / 30)$, the seizures were classified as simple FS. A total of 56.6\% (17/30) of the children had a family history of FS. The children's demographic and clinical features are summarized in Table I. Serum IL-6, TNF- $\alpha$, and IL-1 $\beta$ were higher in febrile seizure group than in the controls $(\mathrm{p}<0.01, \mathrm{p}<0.01$ and $\mathrm{p}<0.05$, respectively) (Table I).

miRNA expression analysis revealed an alteration in children with FS compared to the controls. Serum median miRNA-181, miRNA-155, miRNA-146a, and miRNA-223 levels were higher in febrile seizure group than in the control group, however, the expression levels of miRNAs 146a were significantly increased in FS patients $(\mathrm{p}<0.05)$ (Table II). No differences were found in miRNA expression between FS type and the number of seizures experienced $(\mathrm{p}>0.05)$. There were correlations between levels of TNF- $\alpha$, IL-1 $\beta$ and IL- 6 $(p<0.001)$. However, no relation was found between miRNA expression and TNF- $\alpha$, IL-1 $\beta$ and IL-6 (Table III).

Table I. Demographic, clinical findings and serum TNF- $\alpha$, IL-1 $\beta$, and IL-6 levels of the study group.

\begin{tabular}{|c|c|c|c|}
\hline & Febrile seizures n (\%) & Control group n (\%) & $\mathrm{p}$-value \\
\hline $\begin{array}{l}\text { Age (months) } \\
(\text { mean } \pm \text { SD; min-max) }\end{array}$ & $25.17 \pm 13.23(10-60)$ & $40.16 \pm 18.23(6-60)$ & $\mathrm{p}>0.05$ \\
\hline Gender (boys/girls) & $15 / 15$ & $20 / 10$ & $\mathrm{p}>0.05$ \\
\hline \multicolumn{4}{|l|}{ Source of fever } \\
\hline Upper respiratory tract infections & $23(79.3)$ & $25(83.3)$ & $p>0.05$ \\
\hline Other infections & $7(10.7)$ & $5(16.7)$ & $\mathrm{p}>0.05$ \\
\hline TNF- $\alpha(\mathrm{pg} / \mathrm{ml})$ & 515.58 & 212.58 & $\mathrm{p}<0.01$ \\
\hline Median (min-max) & $(31.96-1127.71)$ & $(39.27-423.42)$ & \\
\hline IL-1 $\beta(\mathrm{pg} / \mathrm{ml})$ & 3923.54 & 1747.13 & $\mathrm{p}<0.05$ \\
\hline Median (min-max) & $(280.83-8220.80)$ & $(221.48-7817.39)$ & \\
\hline IL-6 (pg/ml) & 326.79 & 109.59 & $\mathrm{p}<0.01$ \\
\hline Median (min-max) & $(13.64-728.53)$ & $(21.42-610.72)$ & \\
\hline
\end{tabular}

Table II. MicroRNA 146a, 155, 181 and 223 expression.

\begin{tabular}{|c|c|c|c|c|}
\hline & & Febrile Seizure Group & Control Group & \\
\hline MicroRNA & Ct Value & $\begin{array}{l}\text { Fold Change Median } 2^{-\Delta \Delta C t} \\
\qquad(\min -\max )\end{array}$ & $\begin{array}{l}\text { Fold Change Median } 2^{-\Delta \Delta C t} \\
\qquad(\min -\max )\end{array}$ & $\mathrm{p}$-value \\
\hline MicroRNA-181 & $20.4-28.1$ & $-0.4240(-1.50-1.57)$ & $-0.1490(-1.77-2.17)$ & $p>0.05$ \\
\hline MicroRNA-155 & $26.1-32.2$ & $-0.6200(-1.92-0.88)$ & $-0.0150(-2.69-1.57)$ & $p>0.05$ \\
\hline MicroRNA-146a & $15.2-27.4$ & $-1.0600(-2.39-1.60)$ & $-0.0980(-1.66-2.68)$ & $\mathrm{p}<0.05$ \\
\hline MicroRNA-223 & $17.7-23.7$ & $-0.4010(-1.69-2.15)$ & $-0.0820(-2.04-2.39)$ & $p>0.05$ \\
\hline
\end{tabular}


Table III. The correlations between MicroRNAs; MicroRNAs and cytokines.

\begin{tabular}{|c|c|c|c|c|c|c|c|}
\hline & $\begin{array}{c}\text { MicroRNA- } \\
181\end{array}$ & $\begin{array}{c}\text { MicroRNA- } \\
155\end{array}$ & $\begin{array}{c}\text { MicroRNA- } \\
146 a\end{array}$ & $\begin{array}{l}\text { MicroRNA- } \\
223\end{array}$ & TNF- $\alpha$ & IL-1 $\beta$ & IL-6 \\
\hline \multirow[t]{2}{*}{ MicroRNA-181 } & - & 0.663 & 0.365 & 0.206 & -0.92 & 0.037 & -0.77 \\
\hline & & $<0.001$ & 0.047 & 0.274 & 0.629 & 0.845 & 0.685 \\
\hline \multirow[t]{2}{*}{ MicroRNA-155 } & & & 0.469 & 0.377 & 0.218 & 0.288 & 0.199 \\
\hline & & & 0.009 & 0.040 & 0.247 & 0.123 & 0.291 \\
\hline \multirow[t]{2}{*}{ MicroRNA-146a } & & & & 0.299 & 0.66 & 0.130 & 0.36 \\
\hline & & & & 0.109 & 0.728 & 0.495 & 0.850 \\
\hline \multirow[t]{2}{*}{ MicroRNA-223 } & & & & & 0.095 & 0.157 & -0.039 \\
\hline & & & & & 0.617 & 0.406 & 0.837 \\
\hline \multirow[t]{2}{*}{ TNF- $\alpha$} & & & & & & 0.940 & 0.951 \\
\hline & & & & & & $<0.001$ & $<0.001$ \\
\hline \multirow[t]{2}{*}{ IL-1 $\beta$} & & & & & & & 0.871 \\
\hline & & & & & & & $<0.001$ \\
\hline IL-6 & & & & & & & - \\
\hline
\end{tabular}

The level of miRNA values in predicting patient and control were analyzed using ROC (Receiver Operating Characteristics) curve analysis. When a significant cut-off model was observed, it was presented as $\mathrm{p}$ value, area under curve (AUC) with 95\% confidence interval and cutoff value which has maximum value calculated by dividing sensitivity/specificity. According to these; the cut-off value for miR155 was 0.834 (AUC:0.69, 95\%CI: 0.55-0.82, $\mathrm{p}=0.013$ ). The cut-off value for miR146 was 1.443 (AUC:0.67, 95\%CI: 0.53-0.81, $\mathrm{p}=0.028$ ).

\section{Discussion}

This prospective multicenter study found that the expression levels of miRNA 146a were significantly increased in FS patients. Although previous reports support the hypothesis that miRNAs may contribute to the pathogenesis of epilepsy, studies on the role of microRNAs in the pathophysiology of FS are limited. 5,6,12,13,17-22

Several pro-inflammatory cytokines increase during FS, and, as a consequence, their related miRNAs are also affected. ${ }^{4,6}$ Omran et al. ${ }^{7}$ revealed a negative correlation between IL-1 $\beta$ and miRNA146a expression. This significant increase in miRNA146a expression and its association with the low level of IL-1 $\beta$ might suggest that the purpose of miRNA146a expression is to modulate the inflammation stimulated by IL- $1 \beta$. In contrast, the results of the present study showed a positive correlation between miRNA146a and IL-1 $\beta$ level. The genetic polymorphisms might play a role in this correlation. A study conducted by Issac et al. ${ }^{12}$ revealed that rs2910164 polymorphism in the pre-microRNA-146a gene might be accompanied by an upregulation of proinflammatory cytokines.

The present study found increased miRNA-223 expression in FS patients than controls, without statistical significance. Wang et al. ${ }^{13}$ used the hot water-bath box method with the FS model and examined the role of miRNA-223 in pathogenesis of FS. They found that, compared to normal controls, the expression of miRNA-223 in hippocampal tissues of rats in the FS group was significantly decreased, suggesting low expression levels of miRNA-223. The seizure latency was markedly prolonged while the seizure duration was significantly shortened for rats injected with miRNA-223. The results demonstrate that upregulating the expression of miRNA-223 can improve seizures in FS rats.

Lumbar puncture and cerebrospinal fluid (CSF) analysis are not recommended routinely 
to evaluate FS patients so was not conducted in the present study. In a recent study, Kim et $a l .{ }^{23}$ searched the miRNA profile of CSF in FS patients. They reported 95 miRNAs were significantly higher in patients than in controls and the top 5 highly expressed miRNAs were miRNA-4486, miRNA-6850-5p, miRNA-642$3 p$, miRNA-7107-5p and miRNA-4281. None of these miRNAs were searched in the present study.

FS is associated with a higher risk of epilepsy in general and especially in temporal lobe epilepsy (TLE). ${ }^{24}$ Ren et al. ${ }^{25}$ found miRNA181a to be increased in the temporal lobe tissues of children with intractable epilepsy. In addition, miRNA-146a and miRNA-155 were also significantly upregulated in tissues obtained from patients with MTLE. ${ }^{5-8}$ Another study found that increased miRNA-155 expression was correlated with increased TNF- $\alpha$ in nervous tissue. ${ }^{6}$ However, our results revealed no relationship between miRNAs and proinflammatory cytokines (TNF- $\alpha$, IL- $1 \beta$, IL6).

It has been speculated that modulation of miRNA expression might be a therapeutic model for seizures. In a pilocarpine-induced TLE mouse model, intranasal delivery of miRNA146a antagonist reduced the percentage of animals with seizure onset to $6.7 \%$ and also resulted in an increase in seizure latency. ${ }^{26}$ This may have been the result of a decrease in inflammatory modulators and cytokines, such as nuclear factor kB (NF-kB), TNF- $\alpha$, IL$1 \beta$ and IL-6. An intraventricular injection of miRNA-181a-mimic produced neuronal death in rats, whereas antagomirs against miRNA181a reduced neuronal death after status epilepticus. ${ }^{12,27}$

Viral respiratory infections are commonly associated with FS. Our previous study showed that the most frequently detected viruses were adenovirus, influenza $\mathrm{A}$ and influenza B. ${ }^{16}$ Human miRNAs have been suggested to have their evolutionary origin as an innate immune defense mechanism against viral infection. The
miRNA system modulates viral replication and pathogenesis in several ways: a) respiratory cell miRNAs can affect viral replication; b) some viruses also encode miRNAs, and viralencoded miRNAs target cellular genes involved in cell proliferation and anti-viral response; and c) viral-encoded miRNAs may regulate viral gene expression. ${ }^{11,28}$

A study conducted by Qi et al. ${ }^{29}$ revealed that the expression levels of many miRNAs increase while the levels of more than thirty miRNAs decrease after adenovirus infection, which is one of the common viruses that affect FS patients. A recent study showed a unique expression pattern of microRNAs in influenza infection and decreased expression of miRNA-155, miRNA-146b, miRNA-29, miR-150, miRNA299-5p and miRNA-335. ${ }^{30}$ Huang et al. ${ }^{31}$ showed an accumulation of miRNA-146a, miRNA-7, miRNA-132, miRNA-187, miRNA-200c and miRNA-1275 in lung tissue infected with the influenza A virus. In the present study, we did not search for respiratory viruses; therefore, we cannot analyze the correlation between viruses and miRNA.

The present study has some limitations. miRNA expression was not searched in healthy children. Since most of miRNAs analyzed in the present study were inflammation-related, febrile children were preferred as controls.

In conclusion, miRNAs -146a, -181a, -155 and -223, especially miRNA-146a might be involved in FS pathogenesis. Altered miRNA expression levels might be an adaptive response to inflammation. New therapeutic approaches based on miRNA expression could provide new perspectives for FS treatment.

\section{Acknowledgement}

Authors thank Samet ECE from Diagen Laboratories Ltd, Ankara, Turkey, for their kind support during laboratory analysis. We also thank our patients and their parents. 


\section{Author contribution}

The authors confirm contribution to the paper as follows: study conception and design: KBÇ; data collection: $\mathrm{YK}, \mathrm{GGM}, \mathrm{AE}, \mathrm{PP}, \mathrm{ÇY}$; analysis and interpretation of results: $\mathrm{KBÇ,} \mathrm{DA}, \mathrm{EÇD;}$ draft manuscript preparation: KBÇ, EÇD. All authors reviewed the results and approved the final version of the manuscript.

\section{Ethical approval}

The study was approved by the Local Ethical Committee of Eskisehir Osmangazi University (IRB Number 2020/55, Date: 02.03.2020) and supported by a university research grant.

\section{Source of funding}

This study has been supported by a research grant from Eskisehir Osmangazi University (2019).

\section{Conflict of interest}

No potential conflict of interest was reported by the authors.

\section{REFERENCES}

1. Patterson JL, Carapetian SA, Hageman JR, Kelley KR. Febrile seizures. Pediatr Ann 2013; 42: 249-254.

2. Kwon A, Kwak BO, Kim K, et al. Cytokine levels in febrile seizure patients: a systematic review and meta- analysis. Seizure 2018; 59: 5-10.

3. Bushati N, Cohen SM. microRNA functions. Annu Rev Cell Dev Biol 2007; 23: 175-205.

4. Lovisari F, Simonato M. Gene networks and microRNAs: promises and challenges for treating epilepsies and their comorbidities. Epilepsy Behav 2019: 106488. doi:10.1016/j.yebeh.2019.106488.

5. Aronica E, Fluiter K, Iyer A, et al. Expression pattern of miR-146a, an inflammation-associated microRNA, in experimental and human temporal lobe epilepsy. Eur J Neurosci 2010; 31: 1100-1107.

6. Srivastava A, Dixit AB, Banerjee J, Tripathi M, Sarat Chandra P. Role of inflammation and its miRNA based regulation in epilepsy: implications for therapy. Clin Chim Acta 2016; 452: 1-9.
7. Omran A, Peng J, Zhang C, et al. Interleukin-1 $\beta$ and microRNA-146a in an immature rat model and children with mesial temporal lobe epilepsy. Epilepsia 2012; 53: 1215-1224.

8. Ashhab MU, Omran A, Kong H, et al. Expressions of tumor necrosis factor alpha and microRNA-155 in immature rat model of status epilepticus and children with mesial temporal lobe epilepsy. J Mol Neurosci 2013; 51: 950-958.

9. Carman KB, Calik M, Karal Y, et al. Viral etiological causes of febrile seizures for respiratory pathogens (EFES Study). Hum Vaccin Immunother 2019; 15: 496-502.

10. Auvinen E. Diagnostic and prognostic value of microRNA in viral diseases. Mol Diagn Ther 2017; 21: 45-57.

11. Tahamtan A, Inchley CS, Marzban M, et al. The role of microRNAs in respiratory viral infection: friend or foe? Rev Med Virol 2016; 26: 389-407.

12. Issac MS, Girgis M, Haroun M, Shalaby A. Association of genetic polymorphism of pre-microRNA-146a rs2910164 and serum high-mobility group box 1 with febrile seizures in Egyptian children. J Child Neurol 2015; 30: 437--444.

13. Wang B, Cao X, Lin J, Qian Q, Yu L, Qian Q. Upregulation of microRNA-223 inhibits brain injury and hippocampal neuron apoptosis of rats after febrile seizure through the NLRP3-Caspase-1 signaling pathway. Biomed Pharmacother 2019; 114: 108683.

14. Shinnar S, Glauser TA. Febrile seizures. J Child Neurol 2002; 17(Suppl 1): S44-S52.

15. Willems E, Leyns L, Vandesompele J. Standardization of real-time PCR gene expression data from independent biological replicates. Anal Biochem 2008; 379: 127-129.

16. Livak KJ, Schmittgen TD. Analysis of relative gene expression data using real-time quantitative PCR and the 2(-Delta Delta C(T)) Method. Methods 2001; 25: 402-408.

17. Chu C, Lei X, Li Y, et al. High expression of miR222-3p in children with Mycoplasma pneumoniae pneumonia. Ital J Pediatr 2019; 45: 163.

18. Cui J, Zhou B, Ross SA, Zempleni J. Nutrition, microRNAs, and human health. Adv Nutr 2017; 8: 105-112.

19. Hayes J, Peruzzi PP, Lawler S. MicroRNAs in cancer: biomarkers, functions and therapy. Trends Mol Med 2014; 20: 460-469.

20. Anitha A, Thanseem I. microRNA and autism. Adv Exp Med Biol 2015; 888: 71-83. 
21. Huang Y, Guo J, Wang Q, Chen Y. MicroRNA-132 silencing decreases the spontaneous recurrent seizures. Int J Clin Exp Med 2014; 7: 1639-1649.

22. Reschke CR, Henshall DC. microRNA and epilepsy. Adv Exp Med Biol 2015; 888: 41-70.

23. Kim SH, Yun SW, Kim HR, Chae SA. Exosomal microRNA expression profiles of cerebrospinal fluid in febrile seizure patients. Seizure 2020; 81: 47-52.

24. Asadi-Pooya AA, Nei M, Rostami C, Sperling MR. Mesial temporal lobe epilepsy with childhood febrile seizure. Acta Neurol Scand 2017; 135: 88-91.

25. Ren L, Zhu R, Li X. Silencing miR-181a produces neuroprotection against hippocampus neuron cell apoptosis post-status epilepticus in a rat model and in children with temporal lobe epilepsy. Genet Mol Res 2016; 15. doi: 10.4238/gmr.15017798.

26. Tao H, Zhao J, Liu T, et al. Intranasal delivery of miR146a mimics delayed seizure onset in the lithiumpilocarpine mouse model. Mediators Inflamm 2017; 2017: 6512620.
27. Huang Y, Liu X, Liao Y, et al. MiR-181a influences the cognitive function of epileptic rats induced by pentylenetetrazol. Int J Clin Exp Pathol 2015; 8: 12861-12868.

28. Trobaugh DW, Klimstra WB. MicroRNA regulation of RNA virus replication and pathogenesis. Trends Mol Med 2017; 23: 80-93.

29. Qi Y, Tu J, Cui L, et al. High-throughput sequencing of microRNAs in adenovirus type 3 infected human laryngeal epithelial cells. J Biomed Biotechnol 2010; 2010: 915980

30. Song H, Wang Q, Guo Y, et al. Microarray analysis of microRNA expression in peripheral blood mononuclear cells of critically ill patients with influenza A (H1N1). BMC Infect Dis 2013; 13: 257.

31. Huang L, Ma J, Sun Y, et al. Altered splenic miRNA expression profile in H1N1 swine influenza. Arch Virol 2015; 160: 979-985. 